\title{
Intensification of Weight Loss with the Ketogenic Diet during the Management of a Super Obese: Case Study
}

\author{
Jamile Nobrega Zeraik Abdalla ${ }^{1,2^{*}}$, Lívia Lugarinho Corrêa ${ }^{1}$, Priscilla Gil', \\ Silvia de Freitas ${ }^{1}$, Ignacio Sajoux ${ }^{1}$, German Guzman ${ }^{3}$ and Walmir Coutinho ${ }^{1,2}$
}

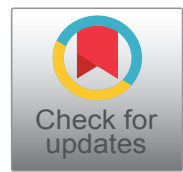

${ }^{1}$ Department of Obesity, Instituto Estadual de Diabetes e Endocrinologia Luiz Capriglione (IEDE), Rio de Janeiro, Brazil

${ }^{2}$ Pontifícia Universidade Católica do Rio de Janeiro (PUC), Rio de Janeiro, Brazil

${ }^{3}$ PronoKal ${ }^{\circledR}$ Group, Barcelona, Spain

*Corresponding author: Jamile Nobrega Zeraik Abdalla, Department of Obesity, Instituto Estadual de Diabetes e Endocrinologia Luiz Capriglione (IEDE), R. Moncorvo Filho, 90, Centro, Rio de Janeiro, RJ, 20230-194, Brazil

\begin{abstract}
Obesity is a chronic disease referred to as a world epidemic. Superobesus management is challenging and requires multidisciplinary follow-up. In this case report, the patient had an initial body mass index (BMI) of $110 \mathrm{~kg} / \mathrm{m}^{2}$ associated with comorbidities such as type 2 diabetes (T2DM). Initial clinical management was performed with changes in lifestyle, through hypocaloric and ketogenic diet, associated with several antiobesity drugs and the introduction of light physical activity. After a total loss of about $140 \mathrm{~kg}$ using only clinical measures, the patient's BMI still remained above 40 $\mathrm{kg} / \mathrm{m}^{2}$, with indication for bariatric surgery. Patient performed Roux-en-Y gastric bypass (RYGB) with greater safety due to previous important weight loss. After the surgery, the patient evolved to the reversion of type T2DM associated with a psychosocial and quality of life improvement.
\end{abstract}

\section{Keywords}

Obesity, Ketogenic diet, Pharmacoteraphy, Bariatric surgery

\section{Introduction}

Obesity is a chronic metabolic disease characterized by a body mass index (BMI) equal to or greater than 30 $\mathrm{kg} / \mathrm{m}^{2}$ and can be attributable to various causes. Over the last four decades the number of cases has increased dramatically, to the point where it is now considered a global epidemic. With an etiology that is a combination of environmental factors together with a genetic predisposition for the disease, excess body weight, primarily when it is characterized by a predominance of visceral fat, can lead to the development and/or exacerbation of various other diseases, such as T2DM, hypertension and dyslipidemia [1,2].

Making changes to one's lifestyle habits, which is essential for treating this disease, should always include regular physical activity with strength-building and aerobic exercises, in addition to a reduced calorie intake [2]. Depending on intake, diets can be divided into: hypocaloric diet, which provides 1200 or more kcal/day, low-calorie diet (LCD), which supplies 800 to $1200 \mathrm{kcal} /$ day, and very-low-calorie diet (VLCD), with an intake of up to $800 \mathrm{kcal} /$ day. If the VLCD is carbohydrate restricted, with an intake of around $50 \mathrm{~g} /$ day, it is classified as a very-low-calorie ketogenic diet (VLCKD) [3].

Pharmacotherapy is recommended for obese patients with a BMI $>30 \mathrm{~kg} / \mathrm{m}^{2}$, or $>27 \mathrm{~kg} / \mathrm{m}^{2}$ with at least one comorbidity. The patient should be evaluated, and therapy initiated according to the risk and benefit of each medication [2].

Evidence indicates that bariatric procedures, with the goal of physically limiting food intake and/or producing nutrient malabsorption, lead to significant short- and long-term weight loss and health benefits with improved metabolic function, appetite reduction and a feeling of fullness [2].

\section{Case Study}

G.A.S., a 33-year-old female patient, reports that since the age of 24 she normally weighed around 100

Citation: Abdalla JNZ, Corrêa LL, Gil P, de Freitas S, Sajoux I, et al. (2019) Intensification of Weight Loss with the Ketogenic Diet during the Management of a Super Obese: Case Study. Clin Med Rev Case Rep 6:254. doi.org/10.23937/2378-3656/1410254

Accepted: January 10, 2019: Published: January 12, 2019

Copyright: (C) 2019 Abdalla JNZ, et al. This is an open-access article distributed under the terms of the Creative Commons Attribution License, which permits unrestricted use, distribution, and reproduction in any medium, provided the original author and source are credited. 
$\mathrm{kg}$, but six years ago, during pregnancy, reached $192 \mathrm{~kg}$. She continued to gain weight postpartum and sought medical help when she reached $330 \mathrm{~kg}$ (BMI: $121.3 \mathrm{~kg} /$ $\mathrm{m}^{2}$ ). She complained of fatigue at the slightest effort and difficulty walking (limit of 10 steps/day) and slept seated due to sleep apnea. She was unaware of any other pathologies. A visual examination of the patient revealed a predominance of gynoid fat distribution, acanthosis nigricans on the neck, intense abdominal and lower limb lymphedema, and an absence of symptoms for Cushing's syndrome. A physical examination was performed with no significant alterations. Anthropometric measurements showed weight: 330 $\mathrm{kg}$; height: $165 \mathrm{~cm}$; waist circumference: $192 \mathrm{~cm}$; hip measurement: $243 \mathrm{~cm}$; neck measurement: $43 \mathrm{~cm}$. Laboratory test assessment established a diagnosis of class III obesity, T2DM and dyslipidemia. After ruling out endocrine and eating disorders by means of a psychiatric evaluation, a hypocaloric diet was initiated by the nutritionist. The endocrinologist prescribed regular medication, gradually increasing the dosage until the final daily dosage was reached for topiramate (200 mg), metformin (2 g), dapagliflozin (10 mg), simvastatin $(20 \mathrm{mg})$ and liraglutide $(1.8 \mathrm{mg})$. It was not possible to increase the liraglutide dosage to $3 \mathrm{mg} /$ day due to the cost, and the decision was made to maintain a dosage of $1.8 \mathrm{mg} /$ day to control T2DM. Dapagliflozin was subsequently discontinued after the patient had an episode of urinary infection and recurrent candidiasis, a condition favoured by lymphedema.

Over the course of a year, with regular monthly consultations, the patient lost $57.8 \mathrm{~kg}$, with a consequent control of comorbidities and significant progress in locomotion, being able to walk about 30 minutes/day. The patient subsequently experienced stabilization of weight loss, and it was decided to initiate a VLCKD through a commercial method (PronoKal ${ }^{\circledR}$ ). During the diet, all medications were maintained with the exception of liraglutide.

The method consists of the use of food substitutes containing $15 \mathrm{~g}$ of protein, $4 \mathrm{~g}$ of carbohydrate and 3 $\mathrm{g}$ of fat. It is divided into three stages: Active, Physiological Adaptation, and Maintenance. The Active Stage consists of a VLCKD $(600-800 \mathrm{kcal} /$ day), low in carbohydrates ( $<50 \mathrm{~g} /$ day) and lipids ( $10 \mathrm{~g} /$ day, administered as 1 tablespoon extra-virgin olive oil), and with high biological value proteins ( 0.8 and $1.2 \mathrm{~g}$ per $\mathrm{kg} /$ ideal weight). The stage is subdivided into three phases: $1,2 \mathrm{a}$ and $2 \mathrm{~b}$. In phase 1 , protein packets are administered at all five meals during the day, along with low-carbohydrate vegetables at lunch and dinner.

During phase $2 \mathrm{a}$, lunch packets are replaced with a low-fat animal protein source. And in phase $2 b$, animal protein substitutes the protein packets during two meals (lunch and dinner). The ketosis phase is maintained until the patient has lost $80 \%$ of the desired weight. As the diet includes an intake of less than 800 $\mathrm{kcal}$, mandatory vitamin and mineral supplements are prescribed (calcium, magnesium, sodium, potassium, omega-3 and a multivitamin) [4]. The ketosis phase is finalized by gradually adding carbohydrates to the diet during the Physiological Adaptation Phase, for a daily intake of up to $1200 \mathrm{kcal}$ (LCD). During this stage the patient loses the remaining $20 \%$ of the weight. The final stage, the Maintenance Stage, consists of a balanced diet including protein, carbohydrates and fat, with a total calorie intake of between 1500 and $2000 \mathrm{kcal} /$ day, the Figure 1 explains the program succinctly [3].

It was decided to keep the patient in the Active Stage (VLCKD) for a period of four months, resulting in a weight loss of $35 \mathrm{~kg}$. Upon finalizing all stages of the method, the patient had lost a total of $52.5 \mathrm{~kg}$ over a period of 12 months. Due to the positive response to the diet and the need for additional weight loss, a second cycle of the PronoKal ${ }^{\circledR}$ Method was initiated. The Active Stage lasted for forty days, with a loss of $15.2 \mathrm{~kg}$, and upon finalizing all stages of the method during the second cycle, the patient had lost $28.8 \mathrm{~kg}$ over a period of ten months, for a total loss of $81.3 \mathrm{~kg}$ with the method. Significant improvement was made to

\begin{tabular}{|c|c|c|c|c|}
\hline \multicolumn{3}{|c|}{$80 \%$ of target weight loss } & $20 \%$ of target weight loss & $\begin{array}{l}\text { Long-term maintenance of } \\
\text { weight loss }\end{array}$ \\
\hline \multicolumn{5}{|c|}{ Multidisciplinary team (dietary counselling I physical activity I psychological support) } \\
\hline \multicolumn{3}{|c|}{$\begin{array}{c}\text { Stage } 1 \\
\text { Active Stage }\end{array}$} & $\begin{array}{c}\text { Stage } 2 \\
\text { Dietary re-education }\end{array}$ & $\begin{array}{c}\text { Stage } 3 \\
\text { Maintenance }\end{array}$ \\
\hline Phase 1 & Phase 2 & Phase 3 & Gradual re-introduction of different foods & Balanced diet \\
\hline \multicolumn{3}{|c|}{$\begin{array}{c}\text { VLCK diet } \\
(600-800 \mathrm{kcal} / \text { day })\end{array}$} & $\begin{array}{c}\text { LC diet } \\
(800-1500 \mathrm{kcal} / \mathrm{day})\end{array}$ & $\begin{array}{c}\text { Maintenance diet } \\
(1500-2250 \text { kcal/day })\end{array}$ \\
\hline
\end{tabular}

Figure 1: Scheme of dietary intervention program for the VLCKD (Extracted from the article: Obesity treatment by very lowcalorie-ketogenic diet at two years: reduction in visceral fat and on the burden of disease). 
Table 1: Evolution of lab parameters and weight (": Glycated hemoglobin; ${ }^{* *}$ : Low-density lipoprotein; ${ }^{* * *}$ : Hight-density lipoprotein).

\begin{tabular}{|l|l|l|l|l|}
\hline Parameter & First Visit & $\begin{array}{l}\text { After Low-Calorie Diet } \\
\text { and Drug Therapy }\end{array}$ & After Ketogenic Diet & After Bariatric Surgery \\
\hline BLOOD GLUCOSE & $156 \mathrm{mg} / \mathrm{dl}$ & $88 \mathrm{mg} / \mathrm{dl}$ & $87 \mathrm{mg} / \mathrm{dl}$ & $89 \mathrm{mg} / \mathrm{dl}$ \\
\hline HBA1C & $6.9 \%$ & $5.3 \%$ & $5.1 \%$ & $4.6 \%$ \\
\hline INSULIN & $38.7 \mathrm{mU} / \mathrm{dl}$ & $36.2 \mathrm{mU} / \mathrm{dl}$ & $12.8 \mathrm{mU} / \mathrm{dl}$ & $4.1 \mathrm{mU} / \mathrm{dl}$ \\
\hline TOTAL CHOLESTEROL & $254 \mathrm{mg} / \mathrm{dl}$ & $209 \mathrm{mg} / \mathrm{dl}$ & $179 \mathrm{mg} / \mathrm{dl}$ & $191 \mathrm{mg} / \mathrm{dl}$ \\
\hline LDL $^{* *}$ & $143 \mathrm{mg} / \mathrm{dl}$ & $120 \mathrm{mg} / \mathrm{dl}$ & $166 \mathrm{mg} / \mathrm{dl}$ & $125 \mathrm{mg} / \mathrm{dl}$ \\
\hline HDL $^{* *}$ & $56 \mathrm{mg} / \mathrm{dl}$ & $36 \mathrm{mg} / \mathrm{dl}$ & $45 \mathrm{mg} / \mathrm{dl}$ & $38.4 \mathrm{mg} / \mathrm{dl}$ \\
\hline TRIGLYCERIDES & $275 \mathrm{mg} / \mathrm{dl}$ & $172 \mathrm{mg} / \mathrm{dl}$ & $104 \mathrm{mg} / \mathrm{dl}$ & $138 \mathrm{mg} / \mathrm{dl}$ \\
\hline CREATININE & $0.9 \mathrm{mg} / \mathrm{dl}$ & $0.77 \mathrm{mg} / \mathrm{dl}$ & $0.9 \mathrm{mg} / \mathrm{dl}$ & $0.68 \mathrm{mg} / \mathrm{dl}$ \\
\hline WEIGHT & $330 \mathrm{~kg}$ & $272 \mathrm{~kg}$ & $188 \mathrm{~kg}$ & $166 \mathrm{~kg}$ \\
\hline BMI & $121.3 \mathrm{~kg} / \mathrm{m}^{2}$ & $100 \mathrm{~kg} / \mathrm{m}^{2}$ & $69.1 \mathrm{~kg} / \mathrm{m}^{2}$ & $61 \mathrm{~kg} / \mathrm{m}^{2}$ \\
\hline
\end{tabular}

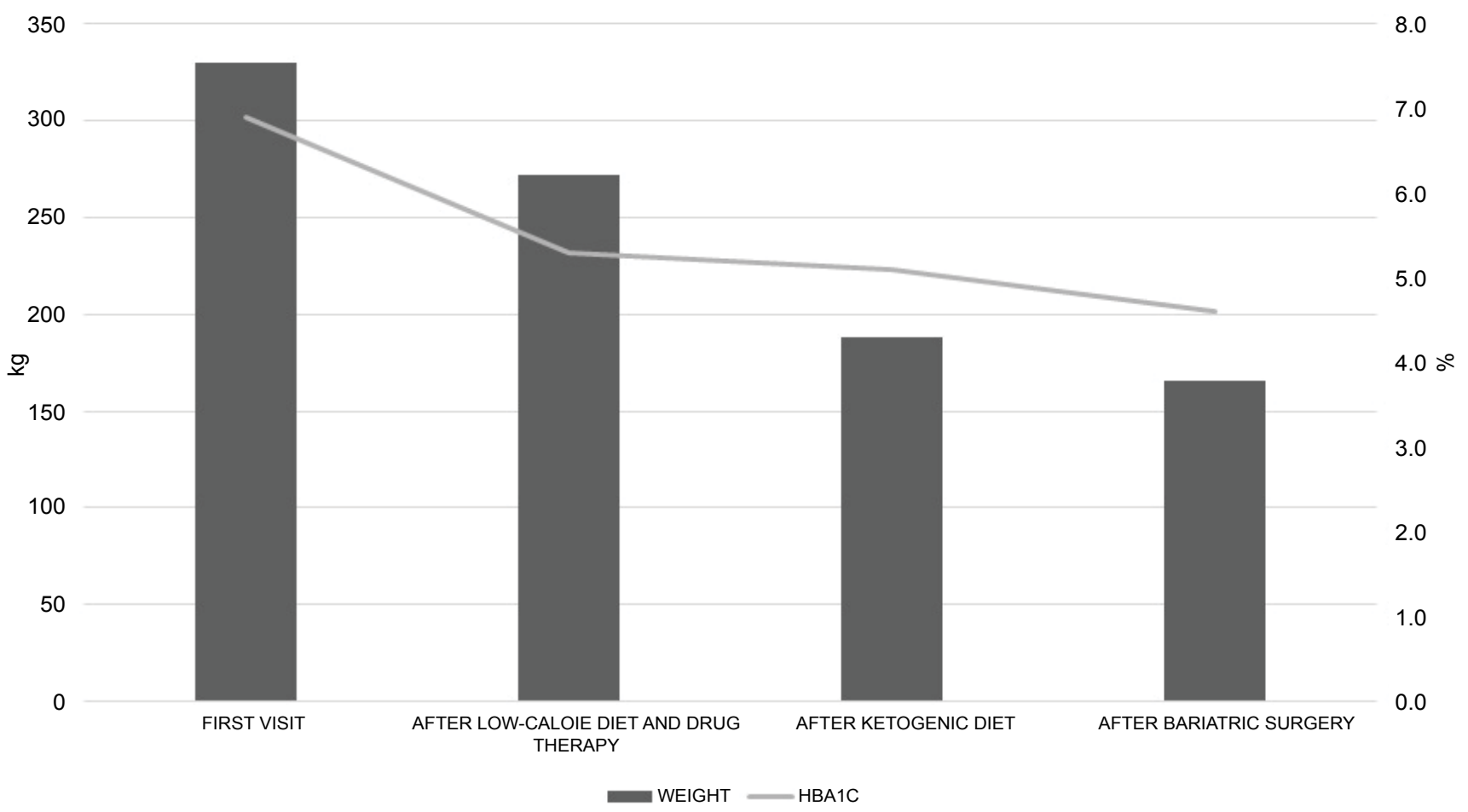

Figure 2: Glycemic control due to weight loss.

locomotive ability, and the patient was able to complete 40 minutes per day of aerobic activity, together with 40 minutes of strength training five days a week.

Even after a total loss of around $140 \mathrm{~kg}$ using clinical measures alone, the patient's BMI still remained above 40. She was then referred for bariatric surgery with a preoperative weight of $188 \mathrm{~kg}$. It was elected to perform a Roux-en-Y gastric bypass (RYGB), consisting of a mixed surgical technique which promotes weight loss through restriction and malabsorption [2], requiring a recommended minimum daily intake of 2 multivitamin and mineral complex capsules (which must contain folic acid, iron and thiamine), $1200-1500 \mathrm{mg}$ of elemental calcium, $3000 \mathrm{IU}$ of vitamin D (titrade to therapeutic levels of 25 -hydroxyvitamin $D>30 \mathrm{ng} / \mathrm{ml}$ ), vitamin $B 12$ (as required to maintain levels within normal range), and $45-60 \mathrm{mg}$ of total iron [5]. The patient is currently taking supplements on a regular basis, and other medications have been discontinued due to significant improvement in metabolic control (Table 1 and Figure 2). Five months after the bariatric surgery was performed, the patient had lost an additional $22 \mathrm{~kg}$, for a final weight of $166 \mathrm{~kg}$ (Figure 3 ), with the possibility of performing cosmetic surgery to repair body contouring (Figure 4).

\section{Discussion}

The causes of weight gain can be attributed to a variety of factors, which bring undesirable consequences for human health. Obesity may be associated with serious psychosocial factors as sustained depressive disorder, which offers more risk to overweight youth and women, and psychological monitoring is required [6]. Therefore, prevention and early treatment are utmost importance to help avoid future complications, and, moreover, there are evidences supporting the effect of physical activity on both short-and long-term weight loss in adults [2]. Many patients with obesity fail to adhere to physical exercise recommendations due to their physical limitations, so it is important to individualize the physical activity. Although calories are the essential 


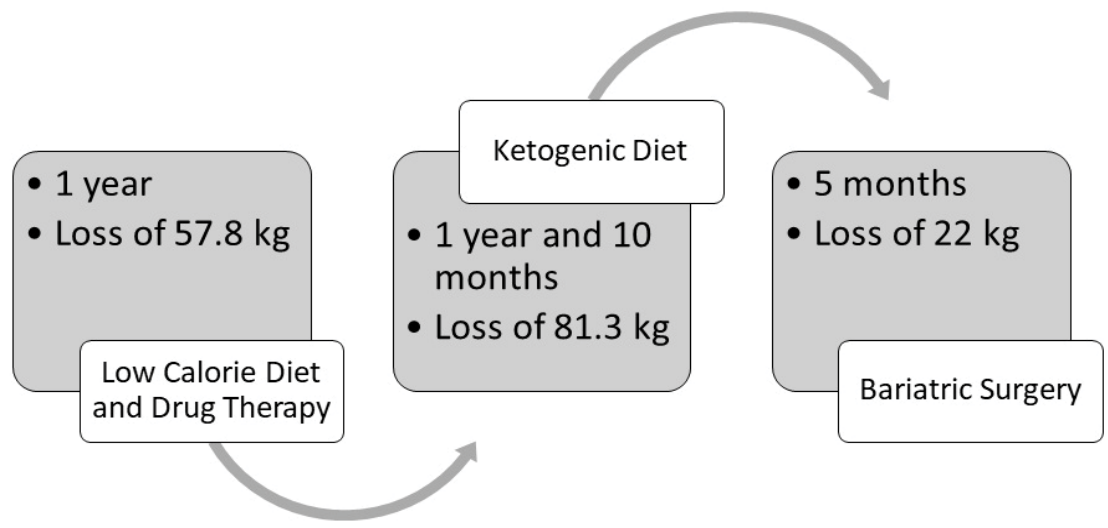

Figure 3: Summarized clinical management approaches.

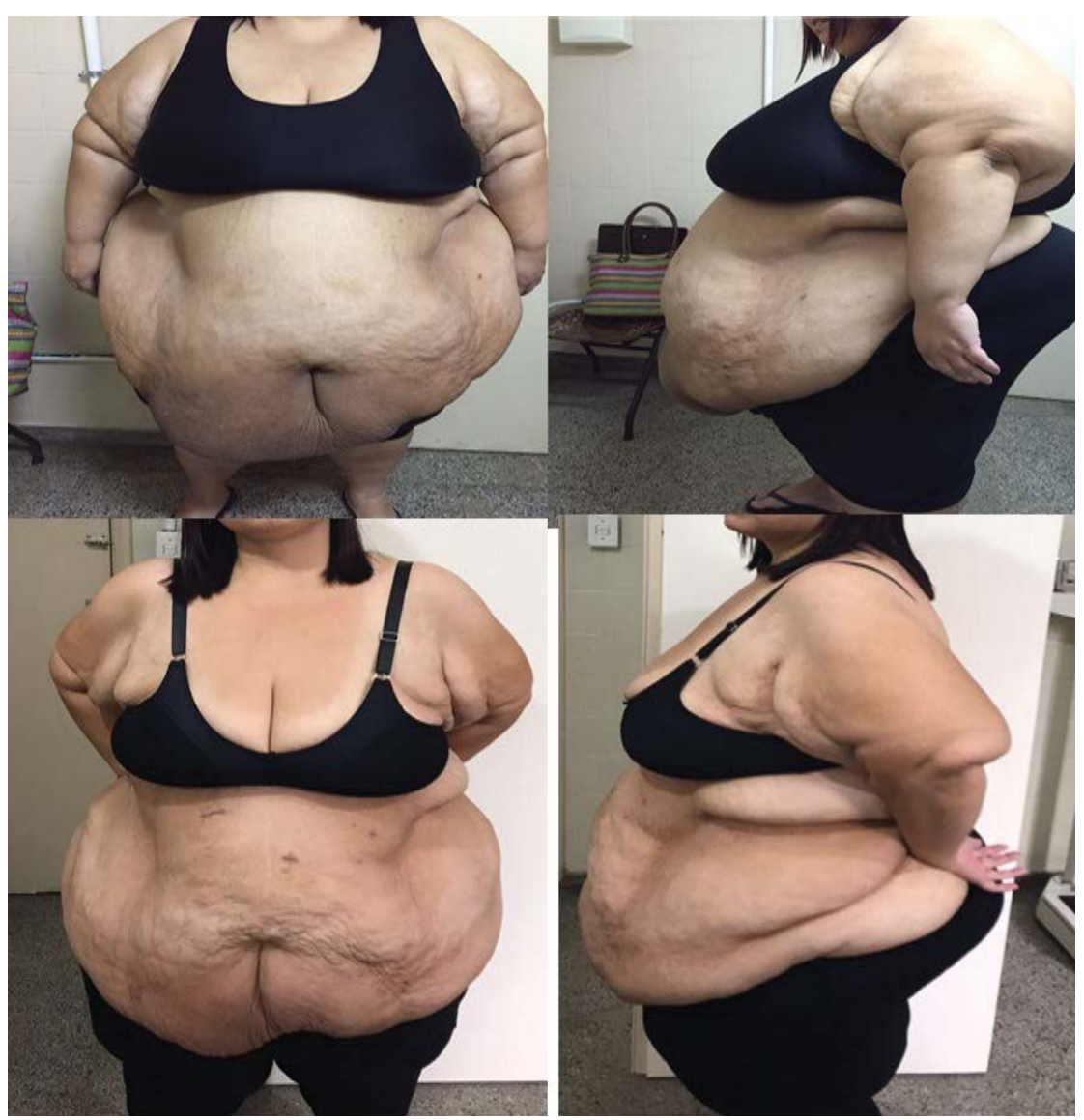

Figure 4: Following drug therapy (before VLCKD) and five months after bariatric surgery.

component of energy balance, it is important to substitute lower calorie healthy foods that can improve the quality of diet [1,2].

Carbohydrate and fat restriction together with a relative increase in protein intake induces a mild to moderate state of ketosis. Through lipolysis, an alternative energy source will be used by the body at the expense of fatty acids and ketone bodies (acetoacetate, b-hydroxybutyrate and acetone) [4].

The ketogenic diet has the additional benefit of reducing hunger, since ketone bodies provide energy and a sense of fullness and well-being [3]. In spite of the higher production of ketone bodies, there are no significant changes in blood $\mathrm{pH}$, anion gap and bicarbonate levels while following the VLCKD, and it is considered a safe nutritional intervention in terms of acid-base balance [7].

In a study comparing patients who followed a VLCKD or a LCD, it was observed that $96 \%$ of the VLCKD group showed a reduction of over $10 \%$ in their weight. In contrast, only $3 \%$ of the LCD group achieved this degree of weight loss. This significant difference was maintained after 4 and 12 months [4]. The continuation of this study showed that the BMI of VLCKD and LCD patients was reduced by 4.4 and 1.9 points after 24 months, respectively. Associated data revealed that the loss of visceral fat was also far greater in the VLCKD group, for a total reduction of $666 \mathrm{~g}$ vs. $200 \mathrm{~g}$ of fat [3].

A study was done to analyses body composition in individuals who followed a VLCKD for four months, the 
objective being to show that during the diet a significant amount of visceral fat is lost, while preserving both muscle mass and muscle strength [8]. For obese patients with T2DM, as in the case described, the study proved the safety and tolerability of the VLCKD because, even though it was a high protein diet, ketosis did not lead to any alteration of renal function (creatinine clearance and albuminuria). In addition, a low carbohydrate intake contributes to glycemic control (serum glucose, glycated hemoglobin and insulin), weight loss, and even discontinuation of antidiabetic drugs [9].

Among the medications prescribed for the patient, topiramate was started off-label for the treatment of obesity. It acts as a sodium- and calcium-channel blocker, enhances GABA activity and inhibits carbonic anhydrase, leading to weight loss through appetite reduction, increased peripheral thermogenesis and lipid oxidation. Liraglutide is a glucagon-like peptide-1 analogue that promotes increased satiety and reduced appetite. Studies show enhanced weight-loss results with a dose of $3 \mathrm{mg} / \mathrm{day}$, and this dosage has been approved for the treatment of obesity [2].

The super obese patient runs a greater risk when undergoing a surgical procedure, and preoperative metabolic control is of paramount importance. A group of patients with class III obesity $\left(53.5 \pm 8.4 \mathrm{~kg} / \mathrm{m}^{2}\right)$, with and without T2DM, were selected for laparoscopic bariatric surgery. They followed a VLCKD as a preoperative diet. The results of this preliminary study reveal that it leads to low cost, rapid weight loss, with fewer side effects than a gastric balloon, a traditional instrument used for weight loss in extremely obese pre-bariatric patients. The diet achieved metabolic control and surgical risk reduction, with no significant differences between patients with and without T2DM [10].

Bariatric surgery is considered the most effective therapeutic option for severe obesity. It is indicated for patients who have not responded to clinical treatment, and who have a BMI greater than or equal to $40 \mathrm{~kg} / \mathrm{m}^{2}$, or greater than or equal to $35 \mathrm{~kg} / \mathrm{m}^{2}$ with associated comorbidities [2]. After surgery, active weight loss results in a metabolic improvement, making it unnecessary to continue with antihypertensive and hypoglycemic drugs in some patients [2].

\section{Conclusion}

The therapeutic treatment of the super obese patient is complex and challenging. It is vital that the patient be accompanied regularly by a trained multidisciplinary team. It is also important to follow more than one weight-loss method to ensure safe, satisfactory and long-lasting results. So, in addition to anti-obesity drugs, we consider the VLCKD to be an excellent tool for the treatment of super obesity, offering an optimum alternative for the bariatric surgery preparation of these patients thanks to the rapid results achieved.

\section{Acknowledgments}

This research was supported by Instituto Estadual de Diabetes e Endocrinologia Luiz Capriglione and PronoKal ${ }^{\circledR}$ Group. We thank our colleagues who provided insight and expertise that greatly assisted the research.

\section{Conflicts of Interest}

The author declares no conflicts of interest.

\section{References}

1. Heymsfield SB, Wadden TA (2017) Mechanisms, pathophysiology, and management of obesity. $\mathrm{N}$ Engl J Med 376: 254-266.

2. Bray GA, Heisel WE, Afshin A, Jensen MD, Dietz WH, et al. (2018) The science of obesity management: An endocrine society scientific statement. Endocr Rev 39: 79-132.

3. Moreno B, Crujeiras AB, Bellido D, Sajoux I, Casanueva FF (2016) Obesity treatment by very low-calorie-ketogenic diet at two years: Reduction in visceral fat and on the burden of disease. Endocrine 54: 681-690.

4. Moreno B, Bellido D, Sajoux I, Goday A, Saavedra D, et al. (2014) Comparison of a very low-calorie ketogenic diet with a standard low-calorie diet in the treatment of obesity. Endocrine 47: 793-805.

5. Mechanick JI, Youdim A, Jones DB, Garvey T, Hurley DL, et al. (2013) Clinical practice guidelines for the perioperative nutritional, metabolic, and nonsurgical support of the bariatric surgery patient - 2013 update: Cosponsored by American Association of Clinical Endocrinologists, The Obesity Society, and American Society for Metabolic \& Bariatric surgery (AACE/ TOS/ASMBS Guidelines). Obesity (Silver Spring) 21: S1-S27.

6. Agrawal P, Gupta K, Mishra V, Agrawal S (2015) The psychosocial factors related to obesity: A study among overweight, obese, and morbidly obese women in India. Women Health 55: 623-645.

7. Gomez-Arbelaez D, Crujeiras AB, Castro Al, Goday A, MasLorenzo A, et al. (2017) Acid-base safety during the course of a very low-calorie-ketogenic diet. Endocrine 58: 81-90.

8. Gomez-Arbelaez D, Bellido D, Castro Al, Ordoñez-Mayan L, Carreira J, et al. (2017) Body composition changes after very low-calorie ketogenic diet in obesity evaluated by three standardized methods. J Clin Endocrinol Metab 102: 488-498.

9. Goday A, Bellido D, Sajoux I, Crujeiras AB, Burguera B, et al. (2016) Short-term safety, tolerability and efficacy of a very low-calorie-ketogenic diet interventional weight loss program versus hypocaloric diet in patients with type 2 diabetes mellitus. Nutr. Diabetes 6: e230.

10. Leonetti F, Campanile FC, Coccia F, Capoccia D, Alessandroni L, et al. (2015) Very low-carbohydrate ketogenic diet before bariatric surgery: Prospective evaluation of a sequential diet. Obes surg 25: 64-71. 